\title{
sciendo

\section{Cost Allocation Model for Net-Zero Energy Buildings under Community-Based Reward Penalty Mechanism}

\author{
Zhijia $\mathrm{HUANG}^{1}$, Yang ZHANG ${ }^{2}$, Yuehong $\mathrm{LU}^{3,4 *}$, Wei WANG ${ }^{5}$, Demin $\mathrm{CHEN}^{6}$, \\ Changlong $\mathrm{WANG}^{7}$, Zafar $\mathrm{KHAN}^{8,9}$ \\ ${ }^{1-3,6,7}$ Department of Civil Engineering and Architecture, Anhui University of Technology, \\ Ma'anshan, 243002, China \\ ${ }^{4,8}$ Department of Electronic, Electrical and Systems Engineering, University of Birmingham, \\ Birmingham, United Kingdom \\ ${ }^{5}$ Modeling and Simulation of Structures, Bauhaus University Weimar, Weimar, Germany \\ ${ }^{9}$ Electrical Power Engineering, Mirpur University of Science and Technology, Mirpur(A.K.), Pakistan
}

\begin{abstract}
The introduction of financial incentives for net-zero energy building/community (ZEB/ZEC) is a potential strategy that facilitates the development of sustainable buildings. In this study, a reward-penalty mechanism (RPM) is firstly proposed for a community that aims to achieve the target of annual zero energy balance. In order to investigate the cost allocated for each building in the community, a cost allocation model by considering the load of these buildings and the levels of zero energy building achieved is further proposed, based on which four typical types of the model is selected and investigated. The economic performance of a building under the four types of allocation model is then compared for a community that consists of $\mathbf{2 0}$ family houses in Ireland. By considering the possible ZEB level ranges in each building, two Cases are conducted (Case 1 - the range is between 0.0 and 1.0; Case 2 - the range is between 0.5 and 1.0). The results show that the $1^{\text {st }}$ model is the simplest one that allocates cost evenly. By contrast, the cost of a building depends on its load in the $2^{\text {nd }}$ model and depends on the ZEB level it achieved in the $3^{\text {rd }}$ model, while it considers the two factors evenly in the $4^{\text {th }}$ model. The proposed cost allocation model is expected to provide a basic guide for the designers of financial incentives as well as experts in the fields of net-zero energy buildings.
\end{abstract}

Keywords - Cost allocation model; economic performance; net-zero energy building/community; reward-penalty mechanism

\section{INTRODUCTION}

Net-zero energy buildings (ZEB/NZEB) has been widely recognized as a potential solution to address the challenges of the increasing environmental and energy problems [1], [2]. Various regulations and legislatives have been proposed to promote ZEB practical applications, which can be observed from the task 40 "Towards net zero energy solar buildings" under the umbrella of international energy agency (IEA) [3], and the goal of

\footnotetext{
* Corresponding author.

E-mail address: luyuehongtuzi@163.com
}

(C)2019 Zhijia Huang, Yang Zhang, Yuehong Lu, Wei Wang, Demin Chen, Changlong Wang, Zafar Khan. 
'nearly net zero energy buildings' for all the new buildings from 2020 under the Directive on Energy Performance of Buildings [4].

In general, passive design strategy (i.e., building envelope, orientation) [5], [6] high efficiency energy-consuming system (e.g. heating, ventilation and air-conditioning system) [7] and renewable energy system (e.g. solar photovoltaic, wind turbine system) [8], [9] are the three key approaches for the design of ZEB. Basically, Energy consumption in building sectors and industry sectors is a vital factor to be much concerned, based on which carbon dioxide emissions can be forecasted [10] and the relative effect of main parameters on energy consumption can be identified [11]. In perspective of building owners, the economic performance of ZEB is a vital factor that has been widely investigated by optimal design and control of renewable energy systems in buildings. In order to minimize the overall initial investment of renewable energy systems an exhaustive search approach was employed by Sun [12] for optimal sizing the renewable energy system and storage system in a ZEB. To treat uncertainty for robust system sizing of ZEB, Zhang and Sun [13] further proposed a responsesurface-model-based system sizing method that can substantially reduce the number of Monte Carlo simulations, and the design option with the maximal overall performance (i.e., annual energy match ratio, self-consumption ratio and initial investment) is finally selected. In the study conducted by Hassoun et al. [14], various power design options were compared in order to achieve the least total net present cost and maximum renewable energy fraction for a standalone net zero energy house located in Lebanon. Besides, a model predictive control using nonlinear algorithm [15] and using mix-integer nonlinear algorithm [16] were proposed by Lu et al. to minimize system operation costs of low/zero energy buildings based on day ahead electricity prices.

The application of renewable energy systems in buildings plays a vital role in the promotion of net-zero energy buildings, however, the cost of ZEB is usually much higher than that of a traditional building mainly due to the high investment of renewable energy systems [17]. A range of incentive policies (i.e. investment subsides, feed-in tariff (FIT), net metering schemes) can be found on the application of renewable energy sources in [18] and [19], and FIT is one widely applied incentives in numerous countries. Many studies have investigated how feed-in-tariff (FIT) affects homer users' decision in terms of: economic aspect [20], investment behaviour for PV selection [21] and WT selection [22], as well as different incentive schemes [23]. For instance, the government firstly introduced a unified feed-in tariff and then determined a sub-regional feed-in tariff (FIT) policy in 2013 for solar power in China [24]. Malaysia introduced the FIT scheme for grid-connected electricity generated by renewables in its 2011 Renewable Energy Act [25]. In 2018, the UK government has announced the new feed-in tariffs for small scale renewable and low carbon electricity, tariff level for new installations of PV $(\leq 10 \mathrm{~kW})$ and Wind $(\leq 50 \mathrm{~kW})$ is $3.79 \mathrm{p} / \mathrm{kWh}$ and $8.24 \mathrm{p} / \mathrm{kWh}$ respectively [26]. The Emissions Trading Scheme has also been proved to be of profound significance for achieving low-cost emission reduction and renewable energy goal [27], [28].

In our previous study, a reward-penalty mechanism has been proposed which focuses on building level [29], [30]. It is recognized that a fundamental role has been increasingly assigned to 'energy communities' in which energy production is based on renewable sources [31]. However, no specific financial incentives have been identified for the promotion of achieving zero energy community and the benefits of its building users until now. This study is therefore conducted to investigate the potential effect of cost allocation model for the buildings in a community under the proposed reward-penalty mechanism based on community level. 


\section{Methodology and Problem Formulation}

A reward-penalty function (1) is proposed for a community that aims to achieve the target of zero energy community. It is developed with the ability of adjusting the cost-effective system selection for a community. As the proposed reward-penalty function follows a quadratic concave curve, a lower ZEC selection will cause a heavier financial penalty for the building owners, and a higher RES integration will bring a greater bonus. A general schematic diagram is shown in Fig. 1, the first step is to identify the building load, its renewable generation and the main key parameters (e.g., RES price, electricity price) for developing the reward-penalty mechanism for this community. Secondly, the initial cost $\left(C_{\text {io }}\right)$ and reward/penalty cost $\left(C_{\mathrm{rp}}\right)$ can be calculated for each level of zero energy community (ZEC). Thus, the corresponding total cost of the community can be derived. Finally, the total cost will be allocated to each building users based on the proposed cost allocation model.

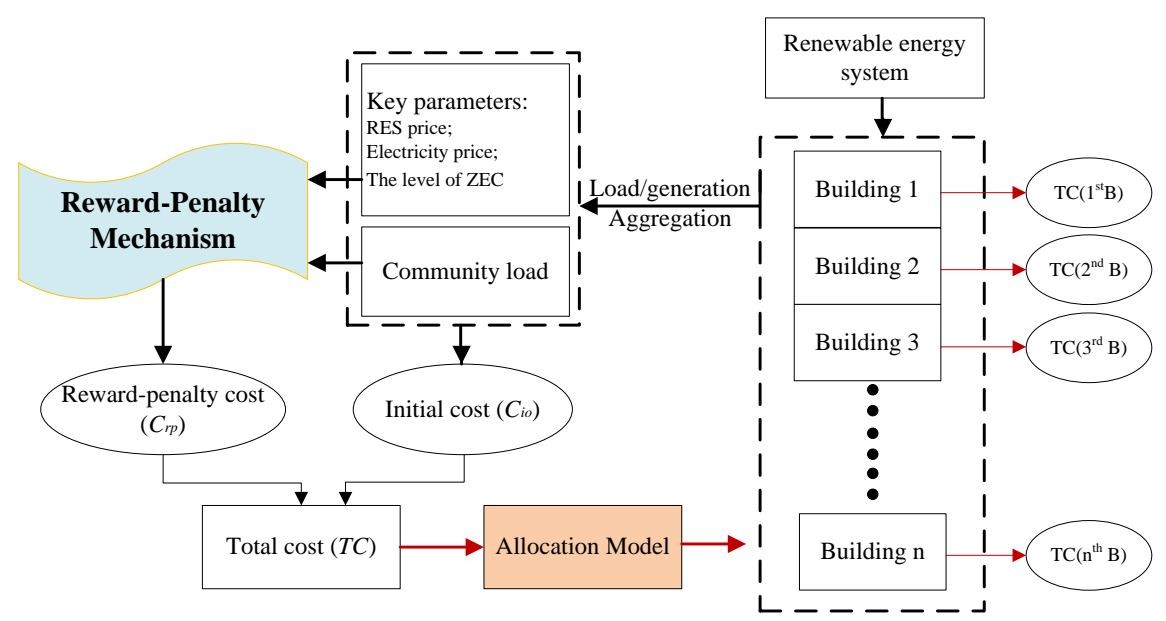

Fig. 1. Schematic diagram of allocation model for community-based RPM.

\subsection{Development of Community-Based RPM}

In this study, PV array and the grid are the two power systems for the community. PV generation has considered the effect of temperature, as calculated in Eq. (1). The PV efficiency is $18 \%$ under the standard test condition and its derating factor is selected to be 0.9 .

$$
E_{\mathrm{pv}, i}=f_{\mathrm{pv}} \frac{I_{\mathrm{T}, i}}{I_{\mathrm{S}}}\left[1+k_{\mathrm{p}}\left(T_{\mathrm{C}, i}-T_{\mathrm{STC}}\right)\right],
$$

where

$E_{\mathrm{pv}, i} \quad \mathrm{PV}$ generation per $\mathrm{kW}$ at the hour $i$;

$f_{\mathrm{pv}} \quad \mathrm{PV}$ derating factor, $\%$;

$I_{\mathrm{S}} \quad$ The radiation under standard test conditions, $1 \mathrm{~kW} / \mathrm{m}^{2}$;

$I_{\mathrm{T}, i} \quad$ Solar radiation on the surface of the $\mathrm{PV}$ array $\left(\mathrm{kW} / \mathrm{m}^{2}\right)$ at the time $i$;

$k_{\mathrm{p}} \quad$ The temperature coefficient of power, $\% /{ }^{\circ} \mathrm{C}$;

$T_{\mathrm{C}, i} \quad \mathrm{PV}$ module temperatures in the current hour, ${ }^{\circ} \mathrm{C}$;

$T_{\text {STC }} \quad$ PV module temperatures under standard test conditions, $25{ }^{\circ} \mathrm{C}$. 
Based on the installation of PV system, a zero-energy level for the community $\left(R_{\mathrm{zec}}\right)$ is defined as the ratio of its renewable generation $\left(E_{\mathrm{PV}}\right)$ to its load $\left(E_{\mathrm{cl}}\right)$, as formulated in Eq. (2). A value of 0.0 for $R_{\text {zec }}$ represents no renewable generation in this community, and a value of 1.0 for $R_{\text {zec }}$ means the community achieved its zero-energy target.

$$
R_{\mathrm{zec}}=\frac{\sum_{i=1}^{8760} E_{\mathrm{pv}, i}}{E_{\mathrm{cl}}}
$$

During application, the grid-connected community is supplied by the power from either PV system or the grid, as shown in Eq. (3). Where, $i$ represents the time from $1 \mathrm{~h}$ to $8760 \mathrm{~h}$, and the electricity price from grid (i.e., the case of non-sufficient RES generation) and to grid (i.e., the case of excess RES generation) is assumed to be an equal value of $0.1 \$ / \mathrm{kWh}$.

$$
E_{\mathrm{cl}, i}=E_{\mathrm{res}, i}+E_{\mathrm{grid}, i}
$$

The annual initial cost of the community $\left(C_{\underline{\text { in }}}\right)$ generally consists of the capital cost of RES and building operation cost, it can be fitted as a linear fitting formula in Eq. (4). Then, the community-based RPM is developed based on the method proposed by Lu et al. [32], and the reward/penalty cost $\left(C_{\mathrm{rp}}\right)$ can be formulated in Eq. (5). The parameters $a, b$, and $c$ in Eq. (5) can be determined by the total cost (TC) in Eq. (6) if given three conditions. In this study, the total cost of the community is assumed to be twice of its initial cost for a selection of 0.0ZEC design, and it is only half of its initial cost for a selection of 1.0ZEC design. In addition, the most economical selection is set to be 1.0ZEC design under the application of RPM.

$$
\begin{gathered}
C_{\mathrm{io}}=b_{1} \cdot R_{\mathrm{zec}}+c_{1} \\
C_{\mathrm{rp}}=a \cdot R_{\mathrm{zec}}^{2}+b \cdot R_{\mathrm{zec}}+c \\
T C=C_{\mathrm{io}}+C_{\mathrm{rp}}
\end{gathered}
$$

\subsection{Development of Cost Allocation Model.}

As illustrated in section 2.1, the total cost of the community is derived for different levels of ZEC design, and it is actually the accumulated total cost of the entire buildings in the community. The total cost is required to be undertaken by the building users in this community, and thus an important step is to develop a cost allocate model. Generally, the building load and the level of zero energy target the building achieved are two key factors that affects the total cost of the community. Therefore, the allocation model can be developed based on the two factors in Eq. (7).

$$
T C\left(k^{\text {th }} B\right)=T C \cdot\left(\alpha \times \frac{E_{\mathrm{bl}}(k)}{E_{\mathrm{cl}}}+\beta \cdot \frac{\frac{1}{R_{z e b, \mathrm{k}}}}{\sum_{1}^{n} \frac{1}{R_{\mathrm{zeb}, k}}}\right),
$$

where, $k=1,2, \ldots n, \alpha+\beta=1.0$. 
Actually, the simplest method is to evenly allocate the total cost for each building, i.e., the $1^{\text {st }}$ model as formulated in Eq. (8). Based on the developed allocation model (7), there are another three typical model types, i.e., the $2^{\text {nd }}$ model concerning only the building load in Eq. (9), the $3^{\text {rd }}$ model concerning only the level of zero energy target it achieved Eq. (10), and the $4^{\text {th }}$ model concerning the two factors evenly in Eq. (11).

$$
\begin{gathered}
1^{\text {st }} \text { Model: } T C 1\left(k^{\text {th }} B\right)=T C \cdot \frac{1}{n} \\
2^{\text {nd }} \text { Model: } \alpha=1.0, \beta=0.0, T C 2\left(k^{\text {th }} B\right)=T C \cdot \frac{E_{b l}(k)}{E_{c l}} \\
3^{\text {rd }} \text { Model: } \alpha=0.0, \beta=1.0, T C 3\left(k^{\text {th }} B\right)=T C \cdot \frac{\frac{1}{R_{\text {zeb }, k}}}{\sum_{1}^{n} \frac{1}{R_{\text {zeb }, k}}}
\end{gathered}
$$

\section{Description of Case Study}

The proposed RPM strategies and cost allocation models are investigated based on a community that consists of 20 family-houses randomly selected in Ireland [33]. The electricity consumption data of these buildings are collected by the smart meter with half-hourly records for more than one year [34]. As shown in Fig. 2, the annual electricity loads of these buildings range from $1476 \mathrm{kWh} / \mathrm{yr}$ to $11191 \mathrm{kWh} / \mathrm{yr}$.

In this study, solar resource and ambient temperature in Dublin, Ireland are selected to evaluate the potential of PV generation. The longitude of Dublin is 53 $26^{\prime} 10^{\prime \prime}$, and the latitude is $6^{\circ} 15^{\prime} 53^{\prime \prime}$. As displayed in Fig. 3, the average annual temperature is identified to be $10.2{ }^{\circ} \mathrm{C}$ and solar irradiation on optimally inclined plate is $3.020 \mathrm{Wh} / \mathrm{m}^{2} /$ day. 


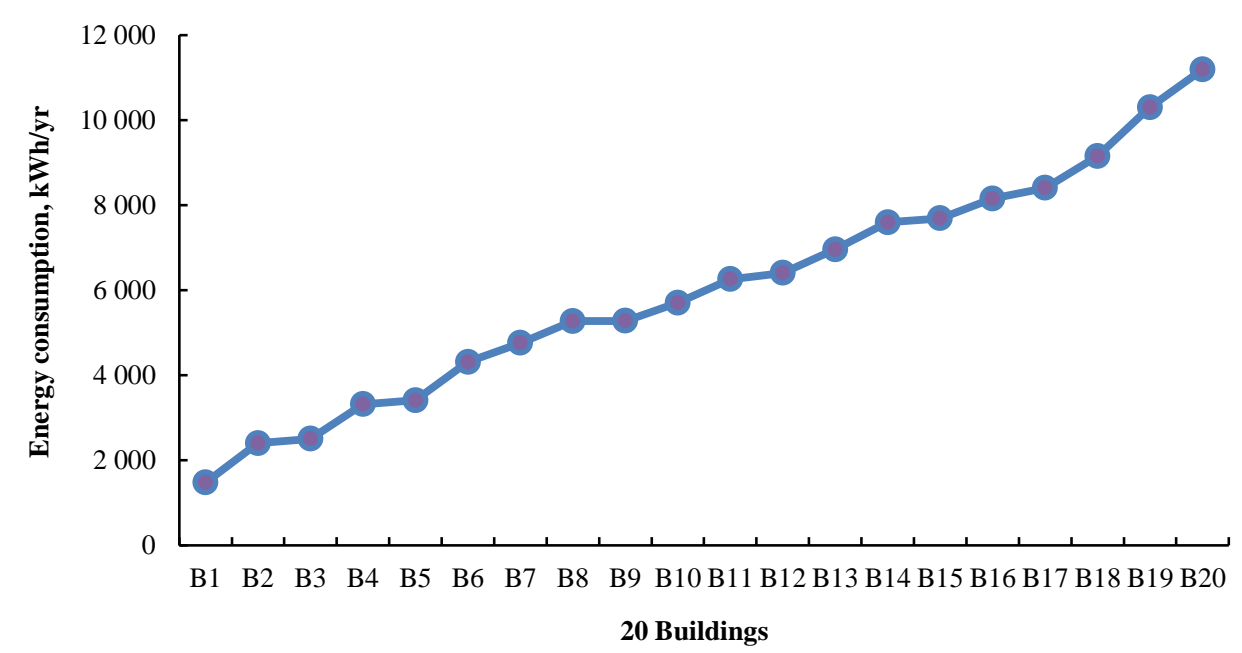

Fig. 2. The annual electricity load of 20 buildings in the community.

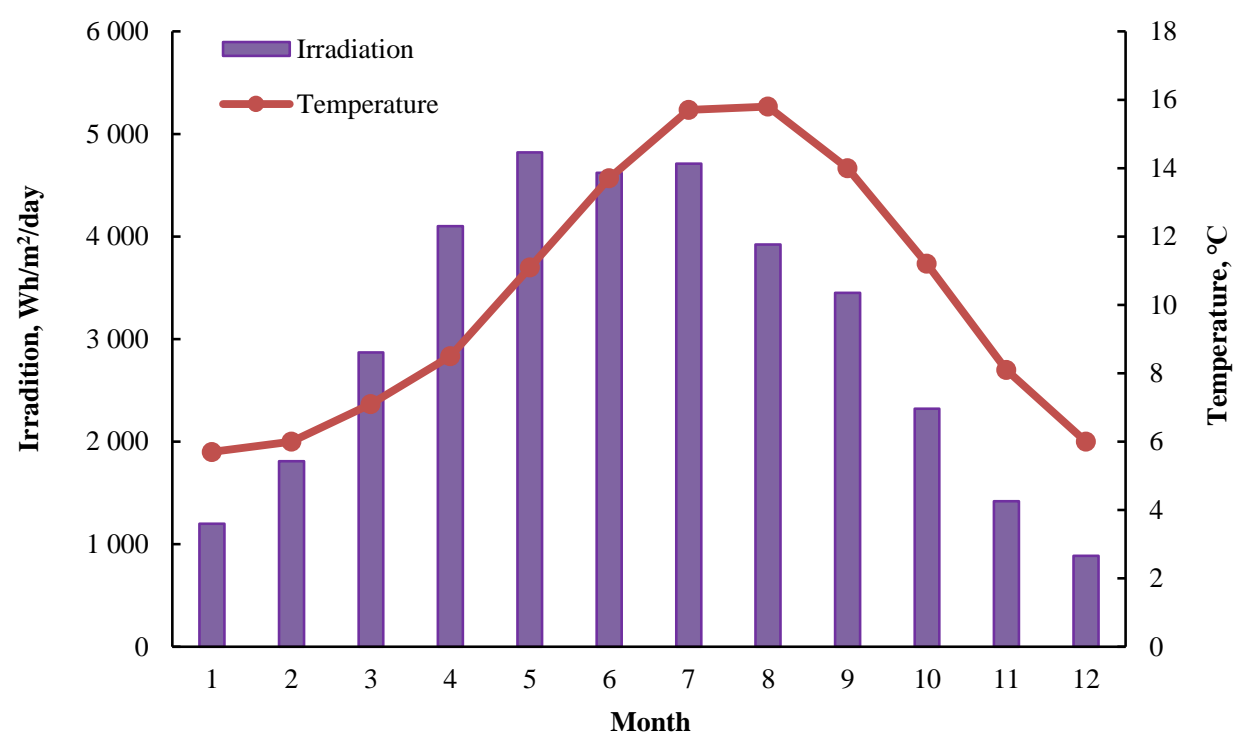

Fig. 3. Average temperature and irradiation on optimally inclined plate in Ireland [35].

\section{Result Analysis}

\subsection{Effect of RPM on Total Cost}

A comparison of the economic performance is presented for the community under the case without RPM $\left(C_{\mathrm{io}}\right)$ and the case with RPM (TC), as shown in Fig. 1. As indicated in section 2.1, the ratio of the total cost to the initial cost is given 2.0 for a 0.0ZEC design and it is 0.5 for a 1.0ZEC design, while the minimum total cost is expected to be at 1.0ZEC design. Under 
this condition, the reward-penalty function is solved, i.e., $C_{\mathrm{rp}}=19180.8 x^{2}-36171 x+12057$. It can be observed that there is not much benefit for the community with a higher ZEC level if no financial incentive is applied. However, a significant cost reduction can be achieved under the developed RPM. More specifically, the minimum total cost of $4934 \$ / y r$ is located at 1.0ZEC design. By contrast, the maximum total cost of $24114 \$ / \mathrm{yr}$ is located a 0.0ZEC design, and it is twice time of the community without RES integration. Consequently, a selection of lower ZEC level will cause a heavier fine whilst a great profit can be expected for a community at a higher RES integration.

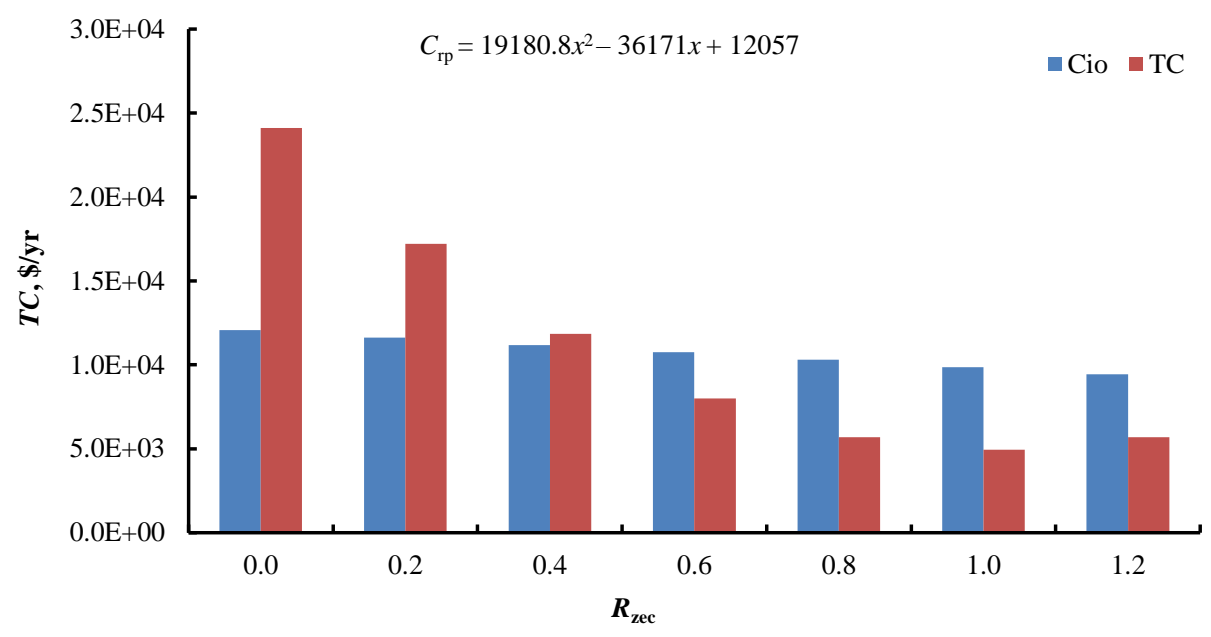

Fig. 4. The total cost of the community under RPM.

\subsection{Cost Allocated for Buildings - Case 1}

As the level of the community to be ZEC is determined by its building users, and the installation of PV system is actually a willing determined by building users. In Case 1, a random probability between 0.0 and 1.0 is assumed as ZEB level achieved by each building. Then, Monte Carlo method is employed to generate a sample of 100 ZEB levels for each building. Finally, the distribution of ZEC level and the total cost of the community are identified as shown in Fig. 5. It is found that the ZEC level and the corresponding total cost are expected to vary between 0.31 and 0.68 , between $6875 \$ / y r$ and $14084 \$ / y r$, respectively. In addition, the cumulative probability of $50 \%$ is observed for ZEC level to be 0.52 , and it is $50 \%$ for the total cost to be $9419 \$ / y r$. 


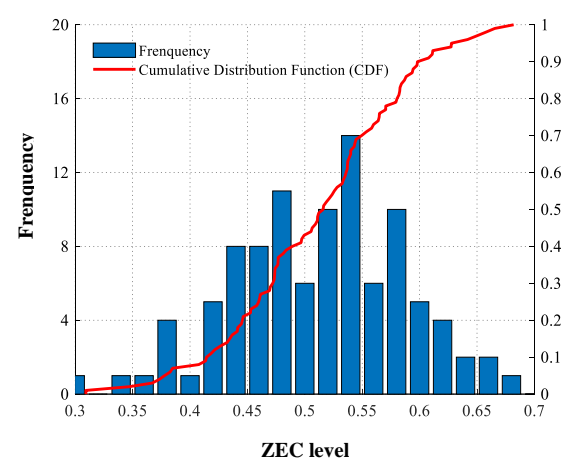

(a)

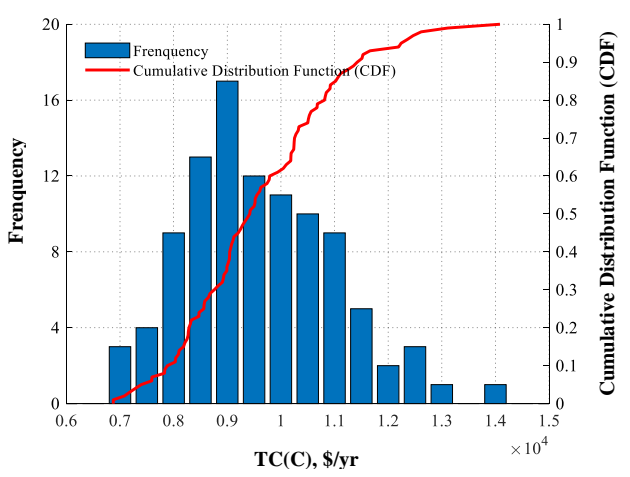

(b)

Fig. 5. (a) Distribution of ZEC level; (b) total cost of the community.

In order to further investigate the benefit for building owners, the total cost of the community is allocated based on four typical types of allocation model as proposed in Eq. (8)-(11). The average cost of each building as well as the community is summarized in Table 1. Under the selection of the $1^{\text {st }}$ allocation model, the total cost is the same for each building with an annual cost of $481 \$ / y r$. Under the selection of the $2^{\text {nd }}$ allocation model, a lowest total cost is required for a lowest building load while a highest total cost is required for a highest building load. This can be found from the $1^{\text {st }}$ Building (load of $1476 \mathrm{kWh}$ ) with an annual cost of $118 \$ / \mathrm{yr}$ and the $20^{\text {th }}$ Building (Load of $11191 \mathrm{kWh}$ ) with an annual cost of $892 \$ / y r$. Under the selection of the $3^{\text {rd }}$ allocation model, a slight difference is found in the cost of each building. This is because the ZEB levels of these buildings are all randomly selected from 0.0 to 1.0 , and the average values under 100 samples are identified between 0.478 and 0.547 . Under the selection of the $4^{\text {th }}$ allocation model, the cost allocated for each building is the mean value of that in the $2^{\text {nd }}$ and the $3^{\text {rd }}$ model.

TABle 1. Average Cost of Each BuILding AND the Community (100 SAmPles)

\begin{tabular}{lllllll}
\hline 20 Buildings & $B L, \mathrm{kWh} / \mathrm{yr}$ & ZEB level & $T C 1, \$ / \mathrm{yr}$ & $T C 2, \$ / \mathrm{yr}$ & $T C 3, \$ / \mathrm{yr}$ & $T C 4, \$ / \mathrm{yr}$ \\
\hline B1 & 1.476 & 0.504 & 481 & 118 & 500 & 309 \\
B2 & 2.403 & 0.494 & 481 & 192 & 464 & 328 \\
B3 & 2.503 & 0.498 & 481 & 200 & 455 & 327 \\
B4 & 3.319 & 0.497 & 481 & 265 & 464 & 364 \\
B5 & 3.412 & 0.501 & 481 & 272 & 656 & 464 \\
B6 & 4.312 & 0.536 & 481 & 344 & 467 & 406 \\
B7 & 4.761 & 0.491 & 481 & 380 & 455 & 417 \\
B8 & 5.275 & 0.529 & 481 & 420 & 604 & 512 \\
B9 & 5.278 & 0.527 & 481 & 421 & 362 & 391 \\
B10 & 5.704 & 0.478 & 481 & 455 & 466 & 460 \\
B11 & 6.261 & 0.499 & 481 & 499 & 690 & 595 \\
\hline
\end{tabular}




\begin{tabular}{lllllll}
\hline B12 & 6.404 & 0.526 & 481 & 510 & 352 & 431 \\
B13 & 6.960 & 0.547 & 481 & 555 & 361 & 458 \\
B14 & 7.595 & 0.496 & 481 & 605 & 417 & 511 \\
B15 & 7.692 & 0.524 & 481 & 613 & 489 & 551 \\
B16 & 8.157 & 0.502 & 481 & 650 & 401 & 526 \\
B17 & 8.406 & 0.519 & 481 & 670 & 382 & 526 \\
B18 & 9.154 & 0.505 & 481 & 730 & 484 & 607 \\
B19 & 10.305 & 0.520 & 481 & 821 & 555 & 688 \\
B20 & 11.191 & 0.509 & 481 & 892 & 586 & 739 \\
Community & 120568 & 0.512 & 9611 & 9611 & 9611 & 9611 \\
\hline
\end{tabular}

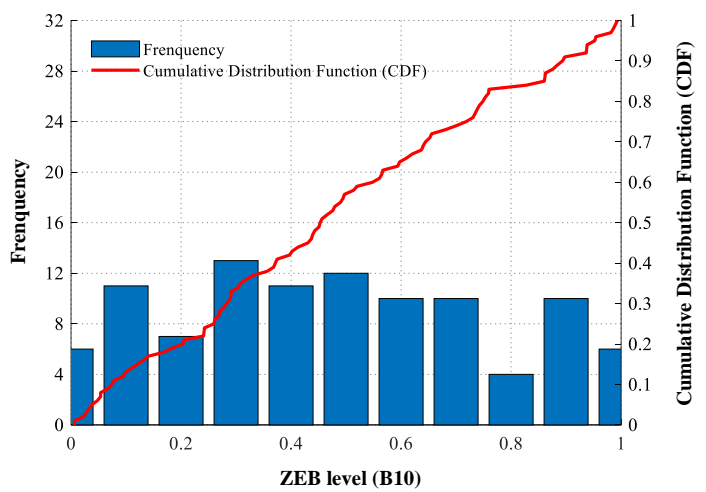

Fig. 6. Distribution of ZEB level for $10^{\text {th }}$ Building. 

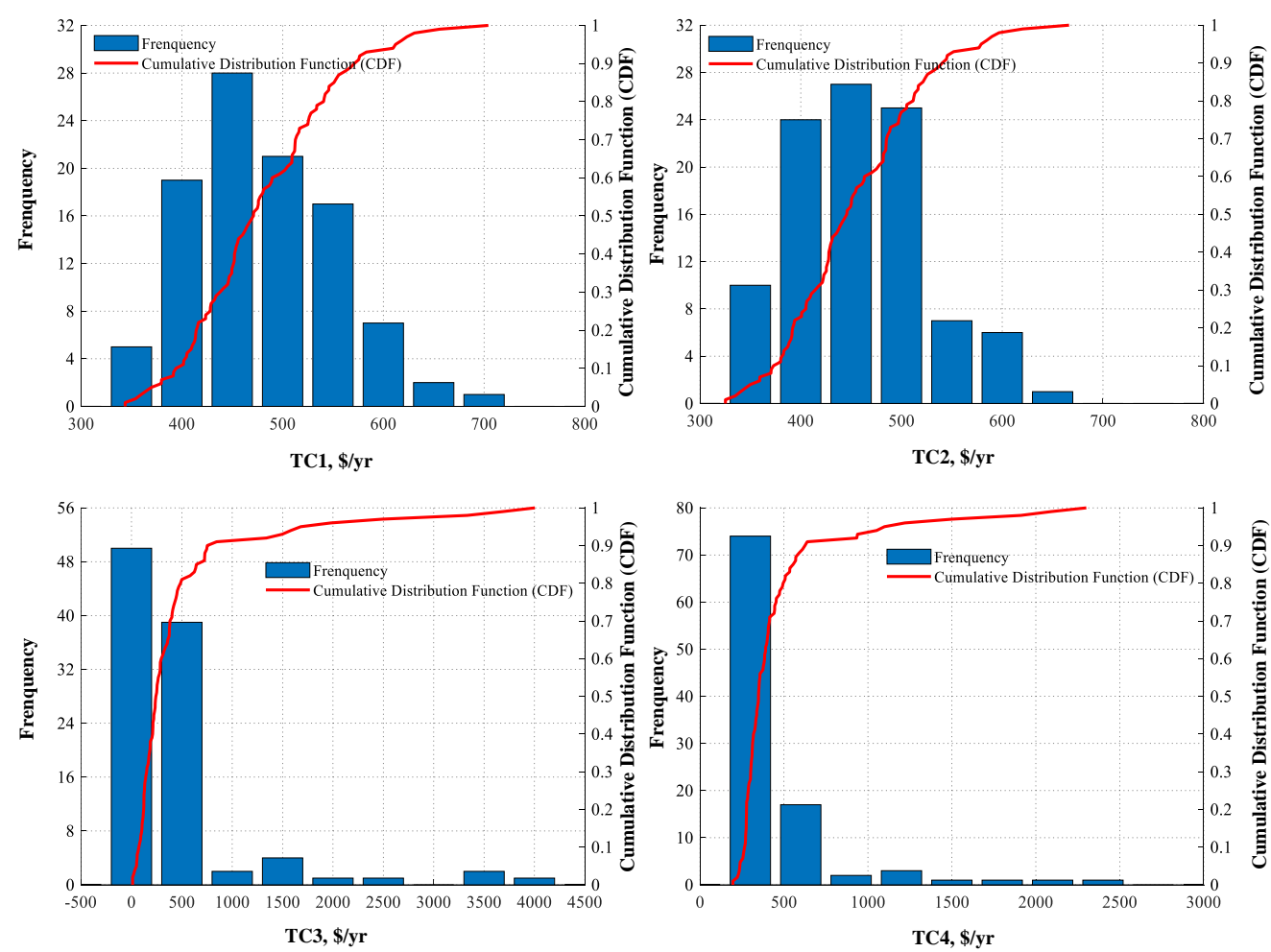

Fig. 7. The cost allocated for $10^{\text {th }}$ Building under four cost allocation models $T C 1, T C 2, T C 3, T C 4$.

A detail distribution of ZEB level and the allocated cost are presented for $10^{\text {th }}$ Building (B10) as shown in Fig. 6 and Fig. 7. In terms of the selection of ZEB level, the cumulative probability of $50 \%$ is observed to be 0.45 for this building. In terms of the cost allocated for this building, a distribution is presented for the four typical types of allocation model. It is interesting to find that the distribution pattern and range of the $10^{\text {th }}$ building cost is similar under the $1^{\text {st }}$ allocation model and the $2^{\text {nd }}$ allocation model. In addition, a little bit low probability is observed for the building users to pay several thousand dollars under the $3^{\text {rd }}$ allocation model and the $4^{\text {th }}$ allocation model.

\subsection{Cost Allocated for Buildings - Case 2}

In Case 2, a random probability between 0.5 and 1.0 is considered as the range of ZEB level for each building. Based on 100 samples simulation, the distribution of ZEC level and the total cost of the community are identified as shown in Fig. 8. It is found that the ZEC level and the corresponding total cost are expected to vary between 0.65 and 0.84 , between $5421 \$ / y r$ and $7259 \$ / y r$, respectively. In addition, the cumulative probability of $50 \%$ is observed for ZEC level to be 0.74 , and it is $50 \%$ for the total cost to be 6201 \$/yr. 


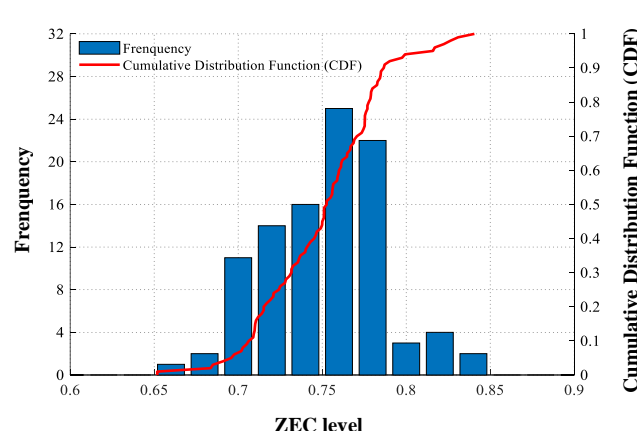

(a)

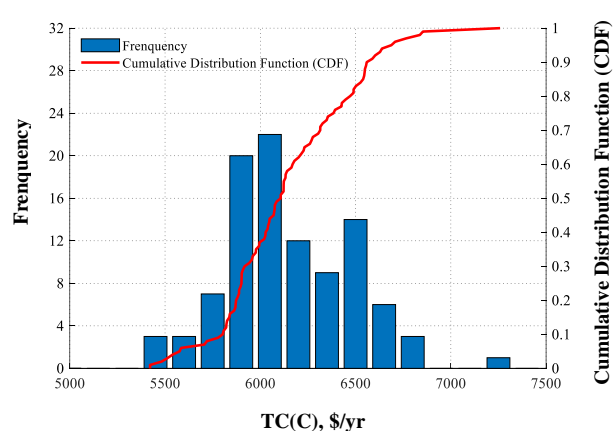

(b)

Fig. 8. (a) Distribution of ZEC level; (b) total cost of the community $T C(\mathrm{C})$.

Similarly to the Case 1, the total cost of the community is allocated based on the four allocation models, as summarized in Table 2 . Under the selection of the $1^{\text {st }}$ allocation model, the same annual total cost is found for each building (307 \$/yr). Under the selection of the $2^{\text {nd }}$ allocation model, the building with low load will be distributed with a low annual cost from the $1^{\text {st }}$ Building (i.e., load of $1.476 \mathrm{kWh}$ and cost of $75 \$ / y r$ ). By contrast, the building with high load will be distributed with a high annual cost from the $20^{\text {th }}$ Building (Load of $11.191 \mathrm{kWh}$ and cost of $571 \$ / \mathrm{yr}$ ). Under the selection of the $3^{\text {rd }}$ allocation model, the costs of the 20 buildings range from 298 \$/yr to 321 \$/yr with the average ZEB levels range from 0.72 to 0.77 . Under the selection of the $4^{\text {th }}$ allocation model, the cost of each building is also seen to be the mean value of that in the $2^{\text {nd }}$ and the $3^{\text {rd }}$ model.

TABLE 2. AVERAge Cost OF EACH BUILDING AND THE COMMUNITY (100 SAMPLES)

\begin{tabular}{lllllll}
\hline 20 Buildings & $B L, \mathrm{kWh} / \mathrm{yr}$ & ZEB level & $T C 1, \$ / \mathrm{yr}$ & $T C 2, \$ / \mathrm{yr}$ & $T C 3, \$ / \mathrm{yr}$ & $T C 4, \$ / \mathrm{yr}$ \\
\hline B1 & 1476 & 0.764 & 307 & 75 & 302 & 189 \\
B2 & 2403 & 0.734 & 307 & 123 & 314 & 218 \\
B3 & 2503 & 0.752 & 307 & 128 & 305 & 216 \\
B4 & 3319 & 0.739 & 307 & 169 & 312 & 241 \\
B5 & 3412 & 0.746 & 307 & 174 & 306 & 240 \\
B6 & 4312 & 0.751 & 307 & 220 & 305 & 263 \\
B7 & 4761 & 0.759 & 307 & 243 & 305 & 274 \\
B8 & 5275 & 0.727 & 307 & 269 & 318 & 294 \\
B9 & 5278 & 0.715 & 307 & 269 & 321 & 295 \\
B10 & 5704 & 0.756 & 307 & 291 & 304 & 297 \\
B11 & 6261 & 0.757 & 307 & 319 & 304 & 312 \\
B12 & 6404 & 0.761 & 307 & 326 & 303 & 315 \\
B13 & 6,960 & 0.765 & 307 & 355 & 302 & 329 \\
B14 & 7595 & 0.770 & 307 & 387 & 298 & 343 \\
\hline
\end{tabular}




\begin{tabular}{lllllll}
\hline B15 & 7692 & 0.753 & 307 & 392 & 305 & 349 \\
B16 & 8157 & 0.717 & 307 & 416 & 321 & 369 \\
B17 & 8406 & 0.751 & 307 & 429 & 308 & 368 \\
B18 & 9154 & 0.764 & 307 & 467 & 302 & 384 \\
B19 & 10305 & 0.748 & 307 & 525 & 309 & 417 \\
B20 & 11191 & 0.764 & 307 & 571 & 301 & 436 \\
Community & 120568 & 0.750 & 6147 & 6147 & 6147 & 6147 \\
\hline
\end{tabular}

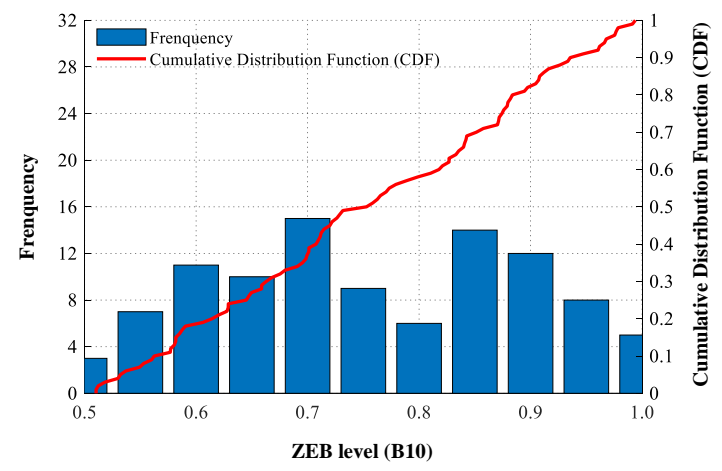

Fig. 9. Distribution of ZEB level for $10^{\text {th }}$ Building. 

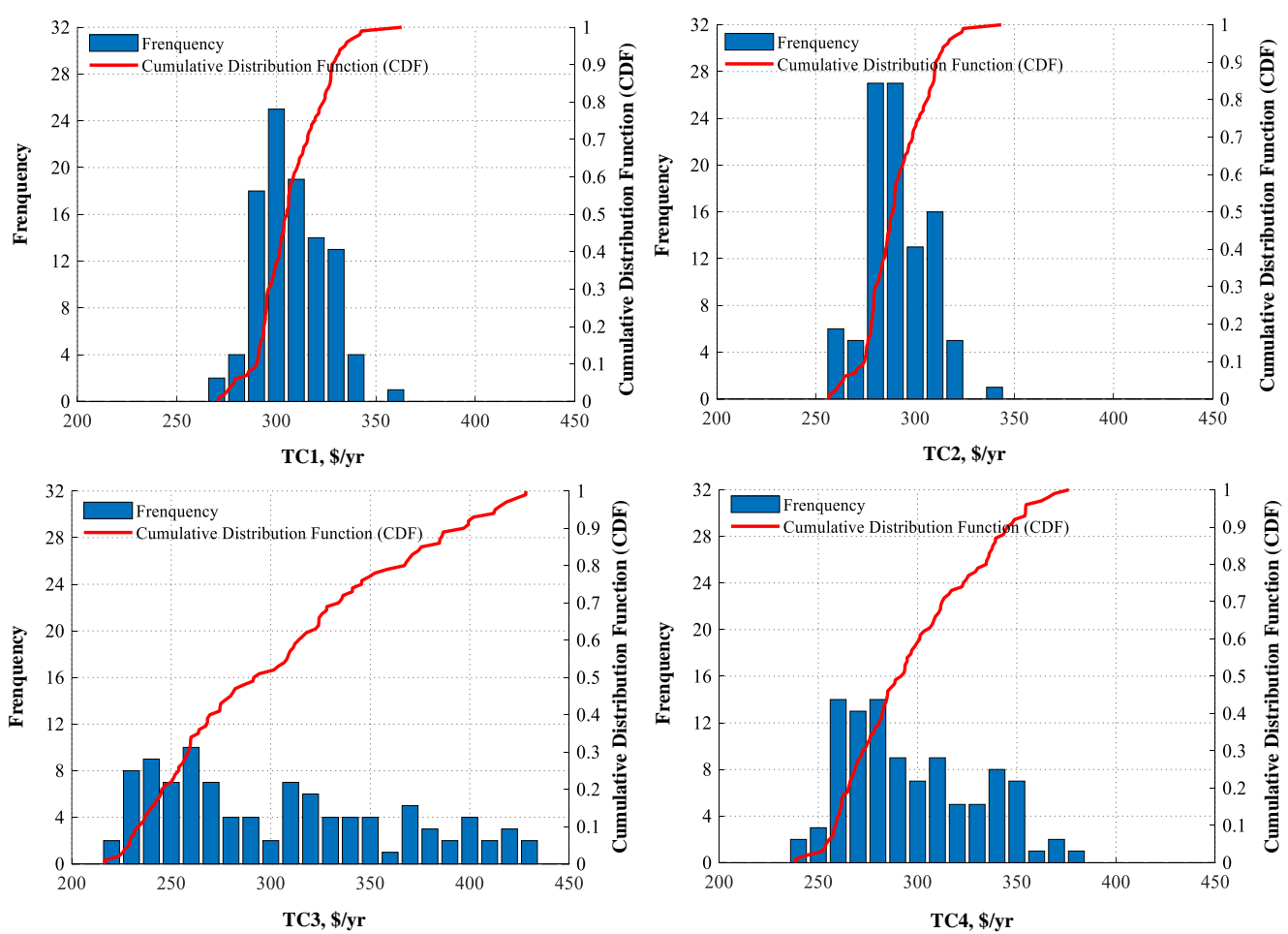

Fig. 10. The cost allocated for $10^{\text {th }}$ Building under four cost allocation models $T C 1, T C 2, T C 3, T C 4$.

A detail distribution of ZEB level and the allocated cost are presented for $10^{\text {th }}$ Building (B10) in Case 2, as shown in Fig. 9 and Fig. 10. The cumulative probability of $50 \%$ is observed to be 0.75 for ZEB level of this building. In addition, although the cost of the building is more centralized in the range of $250 \$ / \mathrm{yr}$ and $450 \$ / \mathrm{yr}$ under the $1^{\text {st }}$ and the $2^{\text {nd }}$ allocation model, the cost differences among the four model are reduced under this case.

\section{Conclusion}

This study aims to develop cost allocation model for the buildings under community-based reward-penalty mechanism, which is conducted based on a community consisting of 20 family houses in Ireland. The economic performance of the community is firstly investigated under the proposed reward-penalty mechanism (RPM). Since the load of these buildings and the levels of zero energy building achieved are two main factors determining the total cost of the community, four typical types of allocation model are proposed for building users in this community.

Since the level of the community to be ZEC is actually determined by its building users, two cases are investigated considering a different ranges of ZEB level, i.e., in case 1, the range of ZEB level is set between 0.0 and 1.0; In case 2, the range of ZEB level is set between 0.5 and 1.0. A similar trend is observed for the cost allocated for each building under the four types of allocation model. Under the selection of the $1^{\text {st }}$ allocation model, the total cost is the same for each building. Under the selection of the $2^{\text {nd }}$ allocation model, a lower building load 
will be allocated with a lower cost, and a higher building load will be allocated with a higher cost. Under the selection of the $3^{\text {rd }}$ allocation model, the costs of these building don't show much differences. Under the selection of the $4^{\text {th }}$ allocation model, the cost allocated for each building is the mean value of that in the $2^{\text {nd }}$ and the $3^{\text {rd }}$ model since it considers the two main factors evenly.

\section{ACKNOWLEDGEMENT}

It is acknowledged that this project received funding from the National Natural Science Foundation of China (Project No. 51608001 and 51478001) to carry out the research work reported in this paper. The authors also acknowledge support provided by the China Scholarship Council (CSC) and research support from the University of Birmingham, United Kingdom.

\section{REFERENCES}

[1] Crawley D., Pless S., Torcellini P. Getting to net zero. ASHRAE 2009:51(9):18-25.

[2] Sun Y., Huang G., Xu X., Lai A. C. Building-group-level performance evaluations of net zero energy buildings with non-collaborative controls. Applied Energy 2018:212:565-576. doi:10.1016/j.apenergy.2017.11.076

[3] SHC Task 40- ECBCS Annex 52. [Online]. Available: http://www.iea-shc.org/task40/

[4] The Directive 2010/31/EU of the European Parliament and of the Council of 19 May 2010 on the energy performance of buildings. Official Journal of the European Union 2010:L153:13-35.

[5] Rodriguez-Ubinas E., Montero C., Porteros M., Vega S., Navarro I., Castillo-Cagigal M., Matallanas E., Guttierez A. Passive design strategies and performance of Net Energy Plus Houses. Energy and Buildings 2014:83:10-22. doi:10.1016/j.enbuild.2014.03.074

[6] Biseniece E., Freimanis R., Purvins R., Gravelsins A., Pumpurs A., Blumberga A. Study of Hygrothermal Processes in External Walls with Internal Insulation. Environmental and Climate Technologies 2018:22(1):22-41. doi:10.1515/rtuect-2018-0002

[7] Wu W., Skye H. M., Domanski P. A. Selecting HVAC systems to achieve comfortable and cost-effective residential net-zero energy buildings. Applied Energy 2018:212:577-591. doi:10.1016/j.apenergy.2017.12.046

[8] Gordon J. M. Optimal sizing of stand-alone photovoltaic solar power systems. Sollar Cells 1987:20(4):295-313. doi:10.1016/0379-6787(87)90005-6

[9] Yang H. X., Zhou W., Lu L., Fang Z. H. Optimal sizing method for stand-alone hybrid solar-wind system with LPSP technology by using genetic algorithm. Solar Energy 2008:82(4):354-367. doi:10.1016/j.solener.2007.08.005

[10] Sutthichaimethee P., Ariyasajjakorn D. Forecast of Carbon Dioxide Emissions from Energy Consumption in Industry Sectors in Thailand. Environmental and Climate Technologies 2018:22(1):107-117. doi:10.2478/rtuect-2018-0007

[11] Bariss U., Bazbauers G., Blumberga A., Blumberga D. System Dynamics Modeling of Households' Electricity Consumption and Cost-Income Ratio: a Case Study of Latvia. Environmental and Climate Technologies 2017:20(1):36-50. doi:10.1515/rtuect-2017-0009

[12] Sun Y. Sensitivity analysis of macro-parameters in the system design of net zero energy building. Energy and Buildings 2015:86:464-477. doi:10.1016/j.enbuild.2014.10.031

[13] Zhang S., Sun Y., Cheng Y., Huang P., Oladokun M. O., Lin Z. Response-surface-model-based system sizing for Nearly/Net zero energy buildings under uncertainty. Applied Energy 2018:228:1020-1031. doi:10.1016/j.apenergy.2018.06.156

[14] Hassoun A., Dincer I. Development of power system designs for a net zero energy house. Energy and Buildings 2014:73:120-129. doi:10.1016/j.enbuild.2014.01.027

[15] Zhao Y., Lu Y. H., Yan C. C., Wang S. W. MPC-based optimal scheduling of grid-connected low energy buildings with thermal energy storages. Energy and Buildings 2015:86:415-426. doi:10.1016/j.enbuild.2014.10.019

[16] Lu Y. H., Wang S. W., Sun Y. J., Yan C. C. Optimal scheduling of buildings with energy generation and thermal energy storage under dynamic electricity pricing using mixed-integer nonlinear programming. Applied Energy 2015:147:49-58. doi:10.1016/j.apenergy.2015.02.060

[17] Lu Y., Wang S., Zhao Y., Yan C. Renewable energy system optimization of low/zero energy buildings using single-objective and multi-objective optimization methods. Energy and Buildings 2015:89:61-75. doi:10.1016/j.enbuild.2014.12.032

[18] Abolhosseini Sh., Heshmati A. The main support mechanisms to finance renewable energy development. Renewable and Sustainable Energy Reviews 2014:40:876-885. doi:10.1016/j.rser.2014.08.013

[19] Bakhshi R., Sadeh J. Economic evaluation of grid-connected photovoltaic systems viability under a new dynamic feedin tariff scheme: a case study in Iran. Renewable Energy 2018:119:354-364. doi:10.1016/j.renene.2017.11.093 
[20] Fridgen G., Kahlen M., Ketter W., Rieger A., Thimmel M. One rate does not fit all: an empirical analysis of electricity tariffs for residential microgrids. Applied Energy 2018:210:800-814. doi:10.1016/j.apenergy.2017.08.138

[21] Liang-Cheng Y., João F. D. R., Hai X. L. Analysis of feed-in tariff policies for solar photovoltaic in China 2011-2016. Applied Energy 2017:203:496-505. doi:10.1016/j.apenergy.2017.06.037

[22] Ritter M., Deckert L. Site assessment, turbine selection, and local feed-in tariffs through the wind energy index. Applied Energy 2017:185(part2):1087-1099. doi:10.1016/j.apenergy.2015.11.081

[23] Muhammad-Sukki F., Ramirez-Iniguez R., Munir A. B., Yasin S. H. M., Abu-Bakar S. H., McMeekin S. G., Stewart B. G. Revised feed-in tariff for solar photovoltaic in the United Kingdom: a cloudy future ahead? Energy Policy 2013:52:832-838. doi:10.1016/j.enpol.2012.09.062

[24] Zhang M. M., Zhou D. Q., Zhou P., Liu G. Q. Optimal feed-in tariff for solar photovoltaic power generation in China: A real options analysis. Energy Policy 2016:97:81-192. doi:10.1016/j.enpol.2016.07.028

[25] Lau K. Y., Muhamad N. A., Arief Y. Z., Tan C. W., Yatim A. H. M. Grid-connected photovoltaic systems for Malaysian residential sector: Effects of component costs, feed-in tariffs, and carbon taxes. Energy 2016:102:65-82. doi:10.1016/j.energy.2016.02.064

[26] Ofgem. Feed-In Tariff (FIT) rates [Online]. Available: https://www.ofgem.gov.uk/environmental-programmes/fit/fittariff-rates

[27] Li L., Ye F., Li Y., Chang C. How will the Chinese Certified Emission Reduction scheme save cost for the national carbon trading system? Journal of Environmental Management 2019:244:99-109. doi:10.1016/j.jenvman.2019.04.100

[28] Rui Q., Xu J., Zeng Z. Carbon emission allowance allocation with a mixed mechanism in air passenger transport. Journal of Environmental Management 2017:200:204-216. doi:10.1016/j.jenvman.2017.05.036

[29] Lu Y., Zhang X., Huang Z., Wang D., Zhang Y. Penalty-cost-based design optimization of renewable energy system for net zero energy buildings. Energy Procedia 2018:147:7-14. doi:10.1016/j.egypro.2018.07.027

[30] Lu Y., Zhang X. P., Huang Z., Wang D., Zhang Y. Impact of introducing penalty-cost on optimal design of renewable energy systems for net zero energy buildings. Applied Energy 2019:235:106-116. doi:10.1016/j.apenergy.2018.10.112

[31] Moroni S., Alberti V., Antoniucci V., Bisello A. Energy communities in the transition to a low-carbon future: A taxonomical approach and some policy dilemmas. Journal of Environmental Management 2019:236:45-53. doi:10.1016/j.jenvman.2019.01.095

[32] Lu Y., Zhang X. P., Li J., Huang Z., Wang C., Luo L. Design of a reward-penalty cost for the promotion of net-zero energy buildings. Energy 2019:180:36-49. doi:10.1016/j.energy.2019.05.049

[33] ISSDA. CER Smart Meter Customer Behaviour Trials Data, accessed via the Irish Social Science Data Archive. CER Electricity [Online]. Available: www.ucd.ie/issda

[34] Khan Z. A., Jayaweera D., Alvarez-Alvarado M. S. A novel approach for load profiling in smart power grids using smart meter data. Electric Power Systems Research 2018:165:191-198. doi:10.1016/j.epsr.2018.09.013

[35] EE535. Appendix A: Irelands Solar Radiation [Online]. Available: https://sites.google.com/site/ee535test/gerardcahill/appendix-a-ireland-solar-potential 